\title{
Acute Necrotizing Encephalopathy: A Rare Case
}

\author{
Patil N. ${ }^{1}$, Kavthekar S. ${ }^{2}$, Karanam A. ${ }^{3}$, Chougule A. ${ }^{4}$, Patil G. ${ }^{5}$
}

${ }^{1}$ Dr. Nivedita Balasaheb Patil, Professor Department of Pediatrics, D.Y. Patil Medical College and Hospital Kadamwadi Kolhapur, Maharashtra, India, ${ }^{2}$ Dr. Saiprasad Onkareshwar Kavthekar, Associate Professor and Fellow in Pediatric Intensive Care Unit, Department of Pediatrics, D.Y. Patil Medical College and Hospital, Kadamwadi, Kolhapur, Maharashtra India, ${ }^{3}$ Dr. Anushna Karanam, Junior Resident, ${ }^{4}$ Dr. Ashok Annasaheb Chougule, Assistant Professor, ${ }^{5}$ Dr. Girish Upendra Patil, Junior Resident, ${ }^{3,4,5}$ above three authors are attached with Department of Pediatrics, D.Y. Patil Medical College and Hospital Kadamwadi Kolhapur, Maharashtra India

Corresponding Author: Dr. Anushna Karanam, Junior Resident, Department of Pediatrics. D. Y. Patil Medical College and Hospital, Kadamwadi Kolhapur, Maharashtra, India. E-mail: karanamanushna@yahoo.co.in

\begin{abstract}
11 year boy was presented withfever, vomiting and GTC with GCS of 6 and neurological signswith shock. Hewas given ventilator and circulatory support. MRI was suggestive of Acute disseminated encephalomyelitis [ADEM]. But acute presentation and rapid deterioration, absence of CSF pleocytosis and raised proteins, raised liver enzymes and thalamic involvement on MRIwas suggestive of Acute Necrotizing Encephalopathy [ANE] than ADEM. He was treated with IV antibiotics, Acyclovir, Methyl Prednisolone and Intravenous immunoglobulin. Inspite of all the vigorous measures, our patient died.
\end{abstract}

Key words: Acute disseminated encephalomyelitis (ADEM), Acute Necrotizing Encephalopathy (ANE), Children

\section{Introduction}

ANE is a rare entity characterized by brain damagethat is preceded by an acute febrile disease, mostly viral infections like Influenza A, Herpes Simplex Virus and human herpes virus[1]. ANE is exclusively seen in healthy young children or infants of East Asian including Japan and Taiwan [2]. Most cases are sporadic, though few cases have recurrent and/ or familial suggesting of inherited pattern, There is no specific treatment and has poor prognosis with less than $10 \%$ of complete recovery[3].

\section{Case Report}

A 11-year boy admitted in our hospital with a history of two days fever, moderate grade, not associated with chills and rigor andrelieved on taking medication along with five episodes of vomiting on the day of admission after which he was taken to the local physician where he had episode of generalized tonic clonic convulsion for which he was referred to our hospital. During transporthe had four episodes of tonic posturing which lasted for about 10-15seconds. There was no history of cough, cold, diarrhea, joint pains, rash also no history of animal bite, recent travel or any vaccinations. He had received orallyParacetamol and Ondansetron by local physician prior to admission.

On admission, his heart rate was $112 \mathrm{bpm}$, respiratory rate was $48 \mathrm{cpm}$, blood pressure 90/60mm $\mathrm{Hg}, \mathrm{SpO} 2 \mathrm{of} 98 \%$, peripheral pulses were feeble and CRT 5 seconds. On neurological examination his Glasgow Coma scale was 6 [E1V2M3]. Pupils were pinpoint not reacting to light. Power was grade 1 in upper and lower extremities. Deep tendon reflexes were brisk and planters wereextensor. Signs of meningeal irritation were absent. Fundus examination revealed left retinal hemorrhages but no papilledema. The child had normal WBC count and platelet count. He hadraised SGOT (157U/L), SGPT (169U/L), ALP (206IU/L) levels. His Renal function tests were normal.Serology for Dengue and Japnease Encephalitis were negative. His CSF revealed high proteins $(551 \mathrm{mg} / \mathrm{dl})$, normal sugar and normal cell count and CBNAT for Tuberculosis was negative.

Manuscript received: $4^{\text {th }}$ December 2018

Reviewed: $14^{\text {th }}$ December 2018

Author Corrected: $20^{\text {th }}$ December 2018

Accepted for Publication: $26^{\text {th }}$ December 2018 
Case Report

On CT scan (Fig1), diffuse white matter hypodensity seen involving extensive areas of bilateral occipito -parietal lobe, bilateral frontal lobes was seen.As child was on ventilator only diffusion weighted and FLAIR sequences MRI were done (Fig 2) which suggested of ill defined hyper intense lesions in bilateral fron to- parietal and occipital temporal predominantly subcortical white matter and cerebellar white matter was seen. Deep grey matter nuclei, basal gangliathalami as well as mid brain, pons were also involved suggestive ADEM. There were no findings suggestive of intracranial hemorrhage or space occupying lesion. Based on the clinical symptoms, a laboratory and MRI finding, diagnosis of acute necrotizing encephalopathy was made.

The child was intubated and ventilated on PCV mode with settings FiO2 100\%, RR 20 PIP 10 and PEEP 5 as his GCS was 6 on admission. Child was empirically started withInjection Ceftriaxone $[100 \mathrm{mg} / \mathrm{kg} / \mathrm{day}]$ and Acyclovir $[20 \mathrm{mg} / \mathrm{kg} /$ day]. He was also given $3 \% \mathrm{NaCl} 5 \mathrm{ml} / \mathrm{kg} /$ dose to reduce intracranial pressure. As the child was hemodynamically unstable, Nor-adrenaline and Dobutaminedrip were started. Child was also received injection methyl prednisolone $20 \mathrm{mg} / \mathrm{kg} / \mathrm{day}$ and IVIg $500 \mathrm{mg} / \mathrm{kg} /$ day 8 hourly. But child did not respond to our vigorous management and deteriorated further and died after 72 hours of admission.

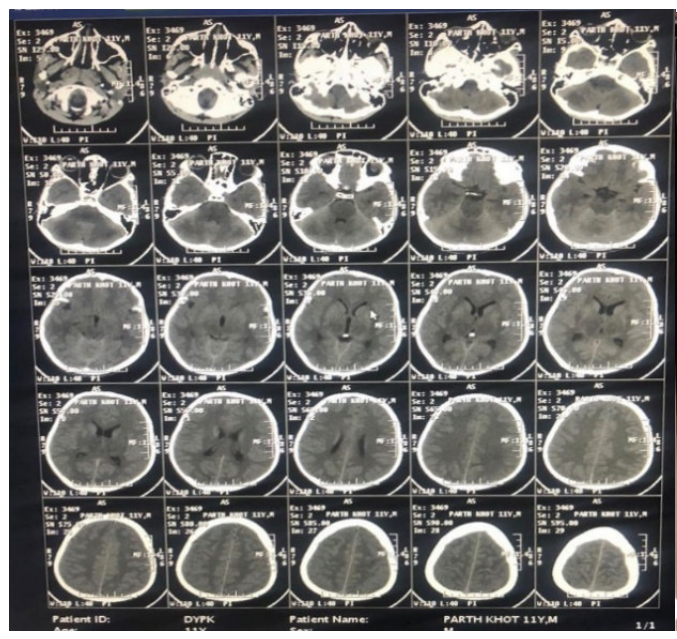

Fig.1

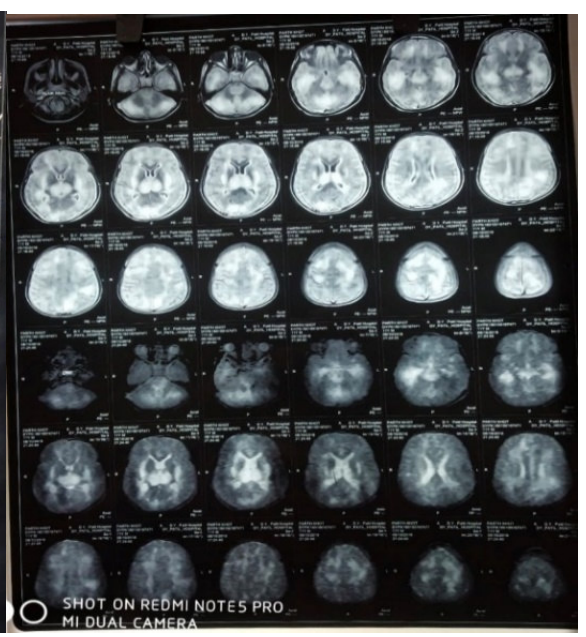

Fig.2

\section{Discussion}

ANE is a rare disease and has rapid deterioration. Encephalopathy is followed by respiratory or gastrointestinal infection and high fever [4]. The prodromal symptoms are followed by seizures, altered consciousness that rapidly progresses to coma, neurological deficit and liver problems [5]. ANE is followed mostly by viral infections. Though etiology is unclear it might be followed by Influenza A, Influenza B, Human Herpes virus infections. ANE may be familial or sporadic. Familial cases may be due to RANBP2 gene mutations, and are known as "infectioninduced acute encephalopathy 3 (IIAE3) [6,7]. It is believed that virus or its variant increases intracranial cytokine production (TNF alpha, IL 1 and 6), which progresses disease rapidly [8].

The disease is characterized by absence of inflammatory cells in brain parenchyma which differentiates from other entities like ADEM and acute hemorrhagic encephalitis. ANE is diagnosed by multiple, symmetrical lesions showing $\mathrm{T} 2$ prolongation in the thalami, frequently with accompanying lesions in the brain stem tegmentum, periventricular white matter, putamen, and cerebellum [9]. In our patient acute clinical presentation with rapid deterioration, absence of CSF pleocytosis and raised proteins normal sugar, raised liver enzymes and thalamic and brainstem involvement on MRIwas suggestiveANE and differentiates from ADEM even if there was predominant white matter affected on MRI [10].

Okumura et al stated that administration of steroids within 24 hours after the onset was related to better outcome of children with ANE without brainstem lesions [11].

\section{Conclusion}

ANE is a rare disease which should be differentiated from ADEM with fatal prognosis in spite of vigorous management.

Funding: Nil, Conflict of Interest: None, Permission from IRC: Yes 
Case Report

\section{References}

1. Mohammad Reza Salehiomra, Hajighorban Nooreddini, Fatemeh Baghdadi. Acute Necrotizing Encephalopathy of Childhood: A Case Report. Iran J Child Neurol. 2013 Spring; 7(2): 51-54

2. Mizuguchi M. Acute necrotizing encephalopathy of childhood: a novel form of acute encephalopathy prevalent in Japan and Taiwan. Brain Dev. 1997 Mar;19(2):81-92.

3. Wong AM, Simon EM, Zimmerman RA, et al. Acute necrotizing encephalopathy of childhood: correlation of MR findings and clinical outcome. AJNR Am J Neuroradiol. 2006 Oct;27(9):1919-23.

4. Neilson D. Susceptibility to Infection-Induced Acute Encephalopathy 3. Gene Reviews. https:// www.ncbi. nlm.nih.gov/books/NBK258641/.

5. Campistol J, Gassió R, Pineda M, Acute necrotizing encephalopathy of childhood (infantile bilateral thalamic necrosis): two non-Japanese cases. Dev Med Child Neurol. 1998 Nov;40(11):771-4.

6. Xiujuan $\mathrm{Wu}$, Wei $\mathrm{Wu}$, Wei Pan, Limin $\mathrm{Wu}$, Kangding Liu \& Hong-Liang Zhang. Acute Necrotizing Encephalopathy: An Underrecognized Clinicoradiologic Disorder. Mediators of Inflammation. 2015; 2015: https://www.hindawi.com/journals/mi/2015/792578/cta/
7. Suri M. Genetic basis for acute necrotizing encephalopathy of childhood. Dev Med Child Neurol. January, 2010; 52(1):4-5. http://onlinelibrary. wiley. com/doi/10.1111/j. 1469-8749. 2009. 03495.x/ full.

8. Skelton BW, Hollingshead MC, Sledd AT, Phillips $\mathrm{CD}$, Castillo M. Acute necrotizing encephalopathy of childhood: typical findings in an atypical disease. PediatrRadiol. 2008 Jul;38(7):810-13.

9. Shinjoh M, Bamba M, Jozaki K, et al. Influenza Aassociated encephalopathy with bilateral thalamic necrosis in Japan. Clin Infect Dis 2000;31:61113Abstract/FREE Full TextGoogle Scholar

10. Makhani Naila, Banwell Brenda. Acquired disorders affecting the white matter. In Swaimans Pediatric Neurology Principles and practice .Swaiman Kenneth, Ashwal Stephan, Ferriero Donna, Schor Nina .5th Edition Chapter 72; Part XI :1055-57

11. Okumura A, Mizuguchi M, Kidokoro H, et al. Outcome of acute necrotizing encephalopathy in relation to treatment with corticosteroids and gammaglobulin. Brain Dev. 2009 Mar;31(3):221-7. doi: 10.1016/j.braindev.2008.03.005. Epub 2008 May 5.

\section{How to cite this article?}

Patil N, Kavthekar S, Karanam A, Chougule A, Patil G. Acute Necrotizing Encephalopathy: A Rare Case. Int J Pediatr Res. 2018;5(12):647-649.doi:10.17511/ijpr.2018.i12.07. 